\title{
Red cell distribution width: a new tool for the severity prediction of sleep apnoea syndrome in children
}

\author{
Daniel Morell-Garcia ${ }^{1,2}$, Núria Toledo-Pons ${ }^{2,3}$, Pilar Sanchis (10) ${ }^{2}$, \\ Josep Miquel Bauça ${ }^{1,2}$, José María Sánchez ${ }^{4}$, José Peña-Zarza $\mathbb{1}^{2,5}$, \\ Paloma Giménez ${ }^{2}$, Javier Pierola ${ }^{2}$, Mónica de la Peña-Bravo ${ }^{2,3}$, \\ Alberto Alonso-Fernández ${ }^{2,3}$ and Antònia Barceló ${ }^{1,2}$
}

Affiliations: ${ }^{1}$ Dept of Laboratory Medicine, Hospital Universitari Son Espases, Palma de Mallorca, Spain. ${ }^{2}$ Institut d'Investigació Sanitària de les Illes Balears, Palma de Mallorca, Spain. ${ }^{3}$ Respiratory Dept, Hospital Universitari Son Espases, Palma de Mallorca, Spain. ${ }^{4}$ Haematology Dept, Hospital Universitari Son Espases, Palma de Mallorca, Spain. ${ }^{5}$ Pulmonology and Sleep Disorders Section, Dept of Pediatrics, Hospital Universitari Son Espases, Palma de Mallorca, Spain.

Correspondence: Daniel Morell-Garcia, Dept of Laboratory Medicine, Hospital Universitari Son Espases, Ctra. Valldemossa 79, 07120 Palma de Mallorca, Balearic Islands, Spain. E-mail: dr.morell.uabagmail.com

\section{ABSTRACT}

Introduction: Red cell distribution width (RDW) is a parameter included in the complete blood count which informs about the size of the circulating red blood cell population and its distribution. In adults, an increase in RDW was shown to be associated both with obstructive sleep apnoea (OSA) and with an increase in cardiovascular mortality. The aim of this study was to determine whether RDW is a potential biomarker for screening children with moderate-severe OSA.

Methods: An observational study in snoring patients was performed. All patients underwent a sleep study and were classified either as simple snorers (apnoea-hypopnoea index (AHI) $<1$ event $\cdot h^{-1}$ ) or as patients with OSA (mild AHI $\geqslant 1$ to $<5$ events $\cdot \mathrm{h}^{-1}$; moderate-severe AHI $\geqslant 5$ events $\mathrm{h}^{-1}$ ). Blood analyses (complete blood count and C-reactive protein) were performed for every individual.

Results: A total of 175 individuals were recruited. The mean age was $8.3 \pm 3.6$ years. Correlation studies between RDW and several sleep-related parameters showed negative significant associations with minimum oxygen saturation, and positive significant associations with oxygen desaturation index $(\geqslant 3 \%$ and $\geqslant 4 \%)$, AHI and the arousal index. A predictive model for paediatric severe OSA (AHI $\geqslant 5$ events $\cdot h^{-1}$ ) was found based on mean corpuscular haemoglobin concentration $(\mathrm{MCHC})<34.9 \mathrm{~g} \cdot \mathrm{dL}^{-1}$ and $\mathrm{RDW}$ $>13.1 \%$ values, adjusting for body mass index $\mathrm{z}$-score and age (area under the curve 0.657; $\mathrm{p}=0.004$ ). In addition, differences were found in eosinophil count and C-reactive protein concentrations among the three subgroups.

Conclusions: In children, RDW stands out as a biomarker associated with the severity of OSA. The use of RDW and MCHC could be a simple but useful tool for the severity prediction of paediatric OSA in snoring patients.

@ERSpublications

Red cell distribution width and mean corpuscular haemoglobin concentration are blood markers associated with the severity of paediatric OSA https://bit.ly/2Asw1xa

Cite this article as: Morell-Garcia D, Toledo-Pons N, Sanchis P, et al. Red cell distribution width: a new tool for the severity prediction of sleep apnoea syndrome in children. ERJ Open Res 2020; 6: 00278-2019 [https://doi.org/10.1183/23120541.00278-2019].

Copyright $\odot E R S$ 2020. This article is open access and distributed under the terms of the Creative Commons Attribution Non-Commercial Licence 4.0. 


\section{Introduction}

Obstructive sleep apnoea syndrome (OSA) is a respiratory disorder characterised by repeated episodes of prolonged upper airway obstruction during sleep [1]. It has a prevalence of $1-5 \%$ in children and can occur at any age [2]. Overnight polysomnography (PSG) is currently considered the gold-standard diagnostic technique [3]. Hypoxaemia sets the presence, risk and progression of many diseases. Several haematological responses to hypoxaemia have been described. Of these, an increased red cell distribution width (RDW) seems to be the most persistent over time. RDW describes the volume heterogeneity of the circulating red blood cell population, and the calculation of this parameter is based on the mean corpuscular volume (MCV).

A review revealed that increased RDW $>14 \%$ is predictive of poor outcome for certain diseases [4] and no difference in RDW has been reported between sexes [5]. Several factors may increase RDW, and the one with the greatest impact is erythropoietin production [6]. Intermittent hypoxia stimulates erythropoietin synthesis and secretion. Increases in endogenous erythropoietin production have been associated with an increase in RDW in patients with coronary disease [7].

In individuals with severe OSA, biomarkers such as RDW and the platelet distribution width (PDW) are related to an increased risk of cardiovascular diseases. The underlying mechanism is hypothesised to be the association between an increased RDW and the deformability of red blood cells, and the repercussion on pulmonary microcirculation [8]. Studies performed in adults showed an association between RDW $>14 \%$ and the decrease in red blood cell deformability, especially in individuals without anaemia [9]. In adults without comorbidities, an increase in RDW was demonstrated in individuals with OSA compared to healthy controls. This observation was independent of OSA severity and not modifiable using continuous positive airway pressure (CPAP) as treatment for patients with OSA [10].

In children, there are numerous studies assessing the classical usefulness of RDW as a biomarker for anaemia and thalassaemia [11-13]. In contrast, in the past decade, there has been a proliferation of studies assessing RDW as a possible tool for predicting other clinical conditions beyond haematological diagnosis [14]. To the best of our knowledge, there are no studies relating RDW to OSA diagnosis in children.

Our hypothesis was that RDW could present a significant clinical value in the screening of paediatric patients with a suspicion of OSA. Therefore, the aim of our study was to determine whether RDW is a potential biomarker for screening children with moderate-severe OSA, and to evaluate the relationship between RDW and apnoea-hypopnoea index (AHI).

\section{Material and methods}

Convenience study period

This is a descriptive observational study in snoring patients. Subjects aged 3-14 years were recruited at the paediatric pulmonology unit of a tertiary care hospital between January 2014 and December 2017.

\section{Subjects}

Patients referred to the paediatric pulmonology unit due to a suspicion of a sleep-breathing disorder were included. Individuals with a chronic disease, genetic syndromes as well as those under conditions potentially affecting sleep or RDW were excluded. For every included individual, parents or legal guardians signed the informed consent, and self-approval was given if aged $>12$ years. The study was evaluated and approved by the ethics committee of our institution and registered as IB 2136/13.

\section{Clinical interview and anthropometric data}

Anthropometric variables were obtained for every patient. Body mass index (BMI) was calculated, and their values were adjusted by means of $\mathrm{z}$-score [15].

During the medical visit, clinical OSA-related variables were collected and a physical exploration was performed. The short version of the validated Paediatric Sleep Questionnaire was filled out [16].

\section{Sleep study}

In all patients a complete polysomnography was performed (Grael, Compumedics, Abbotsford, Australia) at the multidisciplinary sleep unit of our hospital, following the guidelines of the American Academy of Sleep Medicine [17]. Up to six encephalogram channels were studied, as well as chin and anterior tibial electromyogram, bilateral electro-oculogram, heart rate by ECG, airflow monitoring by nasal pressure transducer and oronasal thermistor and chest and abdominal wall movement by respiratory inductance plethysmography. Transcutaneous measurement of arterial oxygen saturation was done by pulse oximetry. All sleep studies were analysed by the same two experts, according to paediatric age validated criteria [17]. K-statistic was 0.930 . 


\section{Definitions}

Apnoea was defined as a decrease in the nasal flow $\geqslant 90 \%$ in at least two respiratory cycles. Hypopnoea was defined as a decrease $\geqslant 30 \%$ followed by an arousal in electroencephalogram or an oxygen desaturation $>3 \%$. The AHI was calculated by adding the number of apnoeas and hypopnoeas, divided by the hours of sleep. Obstructive and central episodes were distinguished and the AHI was referred to the obstructive index. An AHI $<1$ event. $\mathrm{h}^{-1}$ and in the absence of arousals or gas exchange abnormalities was classified as primary snoring, whereas AHI $\geqslant 1$ event $\cdot \mathrm{h}^{-1}$ was classified as OSA. AHI up to 5 events $\cdot \mathrm{h}^{-1}$ was classified as mild OSA and $\geqslant 5$ events $\cdot h^{-1}$ was moderate-severe OSA.

\section{Biochemical study}

In the morning following the sleep study, a blood profile was performed for every individual. Serum C-reactive protein (CRP) was measured using the Architect c16000 platform (Abbott Diagnostics, Abbott Park, IL, USA), with a reference interval of $0.0-0.5 \mathrm{mg} \cdot \mathrm{dL}^{-1}$. Complete blood count (CBC) analyses were carried out using the Cell-Dyn Sapphire (Abbott Diagnostics, USA) in $\mathrm{K}_{2}$ EDTA-whole blood.

\section{Statistical analysis}

A descriptive analysis was performed, calculating absolute and relative frequencies for qualitative variables. Mean \pm SD were used for quantitative parameters. For mean comparison, a t-test was used when appropriate. If not, nonparametric tests were applied. To assess the effect of the presence of OSA on RDW (adjusted by potential confounding factors), a general linear model was used with RDW as a dependent variable and BMI (z-score) and age as independent variables throughout the all-patients sample.

Pearson's correlation coefficient was used to assess correlation between RDW and the other variables. The values deemed to represent a weak relationship are $\leqslant 0.50$, a moderate relationship $0.50-0.76$ and a strong relationship $\geqslant 0.76$.

Univariate and multivariate logistic regressions of risk factors associated to severity (AHI $\geqslant 5$ events.h ${ }^{-1}$ ) were performed. Multivariate analysis was performed using stepwise backward method. Crude and adjusted univariate odds ratios were calculated, and a comparison of the expected and observed frequencies by the Hosmer-Lemeshow goodness-of-fit test was done for the model. Fisher's exact tests were performed for the establishment of the optimal cut-off for each significant variable and receiver operating characteristics (ROC) curve analysis was outlined for the optimal multivariate model.

Taking an estimated incidence of OSA in children of 7\% [18] and adults of 35\% [19], analysis of a minimum of 84 subjects was needed, calculated with an $\alpha$-error of $5 \%$ and statistical power $(1-\beta)$ of $90 \%$, with an enrolment ratio of 1:1.

Statistical significance was set at 5\% bilateral. All data were processed and analysed using SPSS (version 20.0; IBM, Armonk, NY, USA).

\section{Results}

175 individuals with a suspicion of a sleep-breathing disorder were included, with a mean age of $8.3 \pm 3.6$ years. No statistical differences were seen among the three AHI groups in terms of age or BMI z-score.

A total of 76 individuals were included in the group with AHI $<1$ events $\mathrm{h}^{-1}$, with a mean RDW value of 12.1 $\pm 0.7 \%$; in the group with AHI between 1 and $<5$ events $\cdot \mathrm{h}^{-1}, 61$ individuals were included with a mean RDW of $12.1 \pm 0.7 \%$; and in the group with $\mathrm{AHI} \geqslant 5$ events $\cdot \mathrm{h}^{-1}, 38$ individuals were included with a mean RDW of $12.4 \pm 1.2 \%$. Differences among the three groups were not significant $(p=0.134)$. In contrast, statistical significance was found among eosinophil count, the severity of the syndrome and the serum concentration of CRP (table 1).

In most of the $\mathrm{CBC}$ parameters, differences among the three groups were not significant, although the correlations between $\mathrm{AHI}$ and some $\mathrm{CBC}$ parameters were weakly significant, the most outstanding with a positive tendency being the correlation between AHI and RDW ( $\mathrm{r}=0.352 ; \mathrm{p}<0.01)$. Additionally, CRP showed a positive significant moderate correlation after adjustment for BMI z-score (table 1).

RDW weakly correlated with sleep-related parameters, including a negative correlation with minimum oxygen saturation or nadir (\%) and a positive correlation with desaturation indices (total, $\geqslant 3 \%$ and $\geqslant 4 \%$ ), total time of apnoea and arousal index (table 2).

The negative correlations between RDW and other parameters included in the CBC, such as mean corpuscular volume, mean corpuscular haemoglobin and mean corpuscular haemoglobin concentration ( $\mathrm{MCHC})$, thus indicate the interrelationship among parameters participating in the formation and morphology of the red blood cell (table 2). 
TABLE 1 Parameters according to apnoea-hypopnoea index (AHI) severity and adjusted correlations to AHI

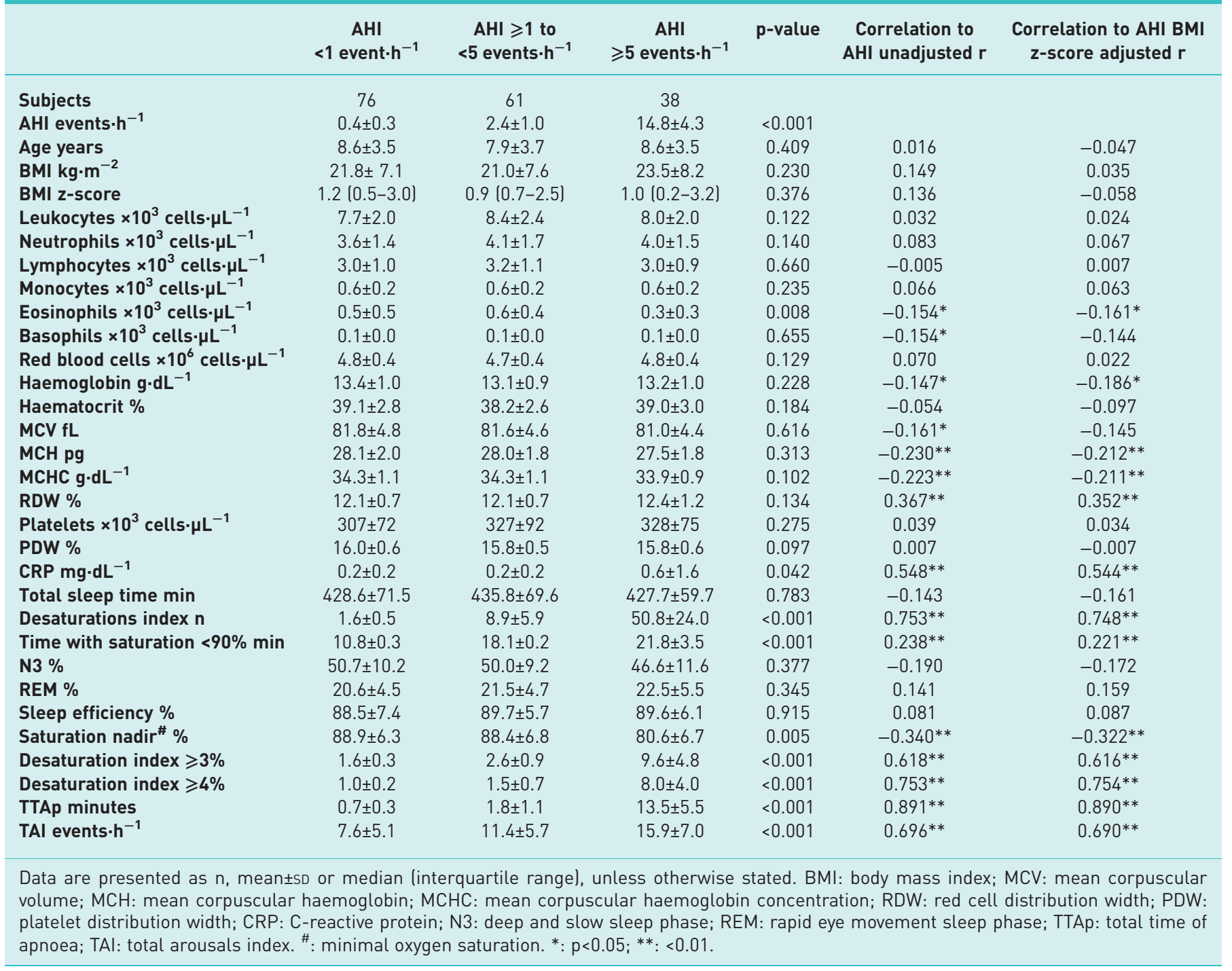

There was no difference in RDW between the three OSA severity groups; however, a significant correlation between them was found. A two-group stratification analysis was performed based on an AHI cut-off value $\geqslant 5$ events $\cdot \mathrm{h}^{-1}$ in order to establish which biochemical and haematological variables could help in the prediction of moderate-severe OSA. The analytical variables with significant differences or statistical tendency ( $p$-value $<0.1$ ) that could be included in a prediction model for OSA severity in children were the eosinophil count, MCHC, RDW and CRP (table 3).

The multivariate analysis was performed using the stepwise backward method; the crude and adjusted odds ratios are indicated in table 4 . Comparison of the expected and observed frequencies by the HosmerLemeshow goodness-of-fit test $(\mathrm{p}=0.652)$ and by ROC curve (area under the curve 0.657, 0.563-0.751; $\mathrm{p}=0.004$ ) indicated a good fit for the model by MCHC and RDW adjusted for BMI z-score and age (figure 1).

Subgroup analysis for patients with AHI $\geqslant 5$ events $\cdot \mathrm{h}^{-1}$ reveals that a cut-off of $\mathrm{RDW}>13.1 \%$ has a specificity of $91 \%$ and a negative predictive value of $82 \%$, and a sensitivity of $25 \%$ with a positive predictive value of $43 \%$, with a likelihood ratio $(+)$ of 2.78 which has a moderate predictive power in relation to the severity of OSA (figure 2).

\section{Discussion}

The mechanism linking RDW to outcomes in different diseases is unknown. Endogenous erythropoietin responds strongly to hypoxaemia, and this molecule could potentially mediate an increase of the RDW response to low oxygenation due the unusual formation of large red blood cells [20]. 


\section{TABLE 2 Correlations of red cell distribution width with clinical and sleep parameters}

\section{Unadjusted correlation} coefficient

\section{BMI kg. $\mathrm{m}^{-2}$}

Eosinophils $\times 10^{3}$ cells $\mu \mathrm{L}^{-1}$

Red blood cells $\times 10^{6}$ cells. $\mu \mathrm{L}^{-1}$

Haemoglobin $\mathbf{g} \cdot \mathbf{d L}^{-1}$

MCV fL

$\mathrm{MCH}$ pg

$\mathrm{MCHC} g \cdot \mathrm{dL}^{-1}$

CRP $\mathrm{mg} \cdot \mathrm{dL}^{-1}$

Total sleep time mins

Desaturations index $n$

Sleep time with saturation

$<90 \% \min$

N3 $\%$

REM \%

Sleep efficiency \%

Saturation nadir \%

Desaturation index $\geqslant 3 \%$

Desaturation index $\geqslant 4 \%$

TTAp minutes

TAl events $\cdot h^{-1}$
BMI z-score adjusted correlation coefficient

$\begin{array}{cc}0.168^{*} & \\ -0.020 & -0.027 \\ 0.354^{* *} & 0.314^{* *} \\ -0.248^{* *} & -0.305^{* *} \\ -0.544^{* *} & -0.533^{* *} \\ -0.656^{* *} & -0.644^{* *} \\ -0.435^{* *} & -0.424^{* *} \\ 0.252^{* *} & 0.243^{* *} \\ -0.050 & -0.036 \\ 0.360^{* *} & 0.348^{* *} \\ 0.159 & 0.133 \\ & \\ 0.062 & 0.092 \\ -0.008 & 0.013 \\ 0.036 & 0.044 \\ -0.262^{* *} & -0.234^{* *} \\ 0.315^{* *} & 0.272^{* *} \\ 0.362^{* *} & 0.327^{* *} \\ 0.351^{* *} & 0.328^{* *} \\ 0.234^{*} & 0.212^{*}\end{array}$

BMI: body mass index; MCV: mean corpuscular volume; $\mathrm{MCH}$ : mean corpuscular haemoglobin; $\mathrm{MCHC}$ mean corpuscular haemoglobin concentration; CRP: C-reactive protein; N3: deep and slow sleep phase; REM: rapid eye movement sleep phase; TTAp: total time of apnoea; TAl: total arousals index. ${ }^{*}: p<0.05$ **: $\mathrm{p}<0.01$.

\section{TABLE 3 Parameters associated with moderate-severe obstructive sleep apnoea}

\begin{tabular}{|c|c|c|c|}
\hline & $A H I<5$ events $\cdot h^{-1}$ & $A H I \geqslant 5$ events $\cdot h^{-1}$ & p-value \\
\hline Subjects $\mathrm{n}$ & 137 & 38 & \\
\hline AHI events $\cdot h^{-1}$ & $1.31 \pm 1.24$ & $14.80 \pm 4.30$ & $<0.001$ \\
\hline Age years & $8.3 \pm 3.6$ & $8.6 \pm 3.5$ & 0.623 \\
\hline BMI $\mathrm{kg} \cdot \mathrm{m}^{-2}$ & $21.5 \pm 7.3$ & $23.5 \pm 8.2$ & 0.141 \\
\hline BMI z-score & $1.1(0.6-2.8)$ & $1.0(0.2-3.2)$ & 0.283 \\
\hline Leukocytes $\times 10^{3}$ cells $\cdot \mu \mathrm{L}^{-1}$ & $8.0 \pm 2.2$ & $8.0 \pm 2.0$ & 0.815 \\
\hline Neutrophils $\times 10^{3}$ cells $\cdot \mu \mathrm{L}^{-1}$ & $3.8 \pm 1.6$ & $4.0 \pm 1.5$ & 0.298 \\
\hline Lymphocytes $\times 10^{3}$ cells- $\mu \mathrm{L}^{-1}$ & $3.1 \pm 1.0$ & $3.0 \pm 0.9$ & 0.990 \\
\hline Monocytes $\times 10^{3}$ cells $\cdot \mu \mathrm{L}^{-1}$ & $0.6 \pm 0.2$ & $0.6 \pm 0.2$ & 0.477 \\
\hline Eosinophils $\times 10^{3}$ cells $\mu \mathrm{L}^{-1}$ & $0.5 \pm 0.5$ & $0.3 \pm 0.3$ & 0.041 \\
\hline Basophils $\times 10^{3}$ cells $\mu \mathrm{L}^{-1}$ & $0.1 \pm 0.0$ & $0.1 \pm 0.0$ & 0.361 \\
\hline Red blood cells $\times 10^{6}$ cells $\mu \mathrm{L}^{-1}$ & $4.8 \pm 0.4$ & $4.8 \pm 0.4$ & 0.365 \\
\hline Haemoglobin $\mathrm{g} \cdot \mathrm{dL}^{-1}$ & $13.3 \pm 0.9$ & $13.2 \pm 1.0$ & 0.927 \\
\hline Haematocrit \% & $38.7 \pm 2.8$ & $39.0 \pm 3.0$ & 0.784 \\
\hline MCV fL & $81.7 \pm 4.7$ & $81.0 \pm 4.4$ & 0.326 \\
\hline $\mathrm{MCH}$ pg & $28.0 \pm 1.9$ & $27.5 \pm 1.8$ & 0.146 \\
\hline $\mathrm{MCHC} \mathbf{g} \cdot \mathrm{dL}^{-1}$ & $34.3 \pm 1.1$ & $33.9 \pm 0.9$ & 0.049 \\
\hline RDW \% & $12.0(11.6-12.3)$ & $12.4(11.7-13.2)$ & 0.050 \\
\hline Platelets $\times 10^{3}$ cells $\cdot \mu \mathrm{L}^{-1}$ & $316 \pm 82$ & $328 \pm 75$ & 0.260 \\
\hline PDW \% & $15.9 \pm 0.6$ & $15.8 \pm 0.6$ & 0.401 \\
\hline CRP $\mathrm{mg} \cdot \mathrm{dL}^{-1}$ & $0.2 \pm 0.2$ & $0.6 \pm 1.6$ & 0.021 \\
\hline
\end{tabular}

Data are presented as $\mathrm{n}$, mean \pm SD or median (interquartile range), unless otherwise stated. AHI: apnoea-hypopnoea index; BMI: body mass index; MCV: mean corpuscular volume; $\mathrm{MCH}$ : mean corpuscular haemoglobin; MCHC: mean corpuscular haemoglobin concentration; RDW: red cell distribution width; PDW: platelet distribution width; CRP: C-reactive protein. 
TABLE 4 Univariate and multivariate logistic regression of risk factors associated to apnoea-hypopnoea index $\geqslant 5$ events $\cdot h^{-1}$

\begin{tabular}{|c|c|c|c|c|c|c|c|}
\hline & $\begin{array}{l}\text { Optimal } \\
\text { cut-off }\end{array}$ & Crude OR & p-value & $\begin{array}{l}\text { Adjusted univariate } \\
\text { OR }\end{array}$ & p-value & Multivariate $\mathrm{OR}^{\#}$ & p-value \\
\hline Age years & & 1.026 (0.927-1.135) & 0.626 & & & & \\
\hline Eosinophils $\times 10^{3}$ cells $\mu \mathrm{L}^{-1}$ & $<0.5$ & $2.232(1.003-4.966)$ & 0.049 & $2.277(1.018-5.090)$ & 0.045 & & \\
\hline CRP $\mathrm{mg} \cdot \mathrm{dL}^{-1}$ & $>0.12$ & $2.591(1.127-5.957)$ & 0.025 & $2.891(1.137-7.348)$ & 0.026 & & \\
\hline $\mathrm{MCHC} g \cdot \mathrm{dL}^{-1}$ & $<34.9$ & $4.674(1.357-16.095)$ & 0.015 & $4.640(1.343-16.027)$ & 0.015 & $3.951(1.130-13.840)$ & 0.032 \\
\hline
\end{tabular}

Respiratory event-associated desaturations are seen more frequently in adults than in children, and the intermittent hypoxia is the hallmark feature and the most important pathophysiological pathway of OSA. In this regard, in our population, oxygen desaturation index $>3 \%$ and $>4 \%$ correlate with RDW.

Intermittent hypoxia is believed to be the most important factor causing systemic inflammation, and has also been strongly related with activation of $\mathrm{NF}-\kappa \mathrm{B}$ and the upregulation of production of many pro-inflammatory mediators [21-23]. CRP is a good predictor of OSA, and is independently associated with AHI, even after adjusting for age and BMI [24]. Paediatric OSA has a relatively short time of symptomatology until diagnosis, which may explain our findings regarding a weak relationship between CRP and RDW.

When OSA groups were defined as either AHI $<1$ event $\cdot h^{-1}$ or AHI $\geqslant 1$ events $\cdot \mathrm{h}^{-1}$, no differences were found in RDW between simple snoring and OSA patients. However, when another severity group was defined (AHI $\geqslant 5$ events $h^{-1}$ ), these differences almost reached statistical significance. When we observe the distribution of RDW in these two subgroups, in which the 75th percentile of children with AHI $<5$ events. $\mathrm{h}^{-1}$ was $12.3 \%$ and that of AHI $\geqslant 5$ events $\cdot \mathrm{h}^{-1}$ was $13.2 \%$, a cut-off of $13.1 \%$ can distinguish those snoring children with a higher probability of having a severe OSA. Although RDW seems to have a low sensitivity for identifying children with severe OSA, values of RDW $>13.1 \%$ have a high specificity to help identify those who are more likely to have moderate-severe OSA.

Therefore, we could conclude that a more severe OSA was necessary to bring to light the effects of intermittent hypoxia. These facts reveal the importance of the need for finding predictive biomarkers for therapeutic decisions in children, especially in the mild OSA group (AHI $\geqslant 1$ to $<5$ events $\cdot \mathrm{h}^{-1}$ ), since we have found differences only in the group with greater severity. Guidelines recommend individualised decisions in mild OSA patients, depending on the risk factors [3].

In adults, recent studies have used the combination of glycated haemoglobin, erythropoietin and CRP for the diagnostic screening of OSA and its severity, with sensitivity $>80 \%$ [25]. CPAP therapy has been

FIGURE 1 Receiver operating characteristic curve larea under the curve $=0.657 ; p=0.004$ ) indicating a good fit for the prediction model for severity of paediatric obstructive sleep apnoea lapnoea-hypopnoea index $\geqslant 5$ events $\cdot h^{-1}$ ) with mean corpuscular haemoglobin concentration $<34.9 \mathrm{~g} \cdot \mathrm{dL}^{-1}$ and red cell distribution width $>13.1 \%$, adjusted by age and body mass index z-score.

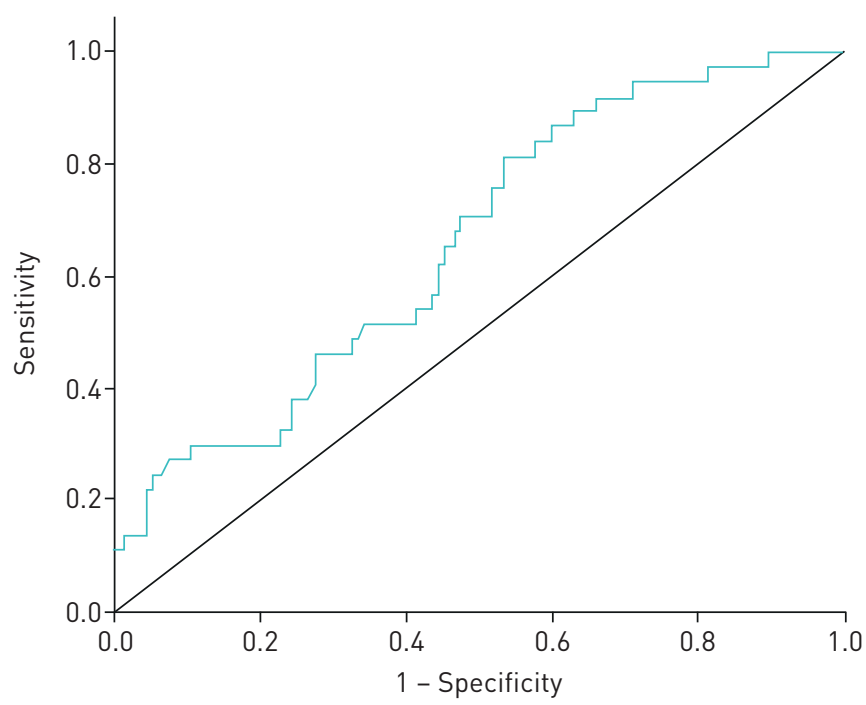




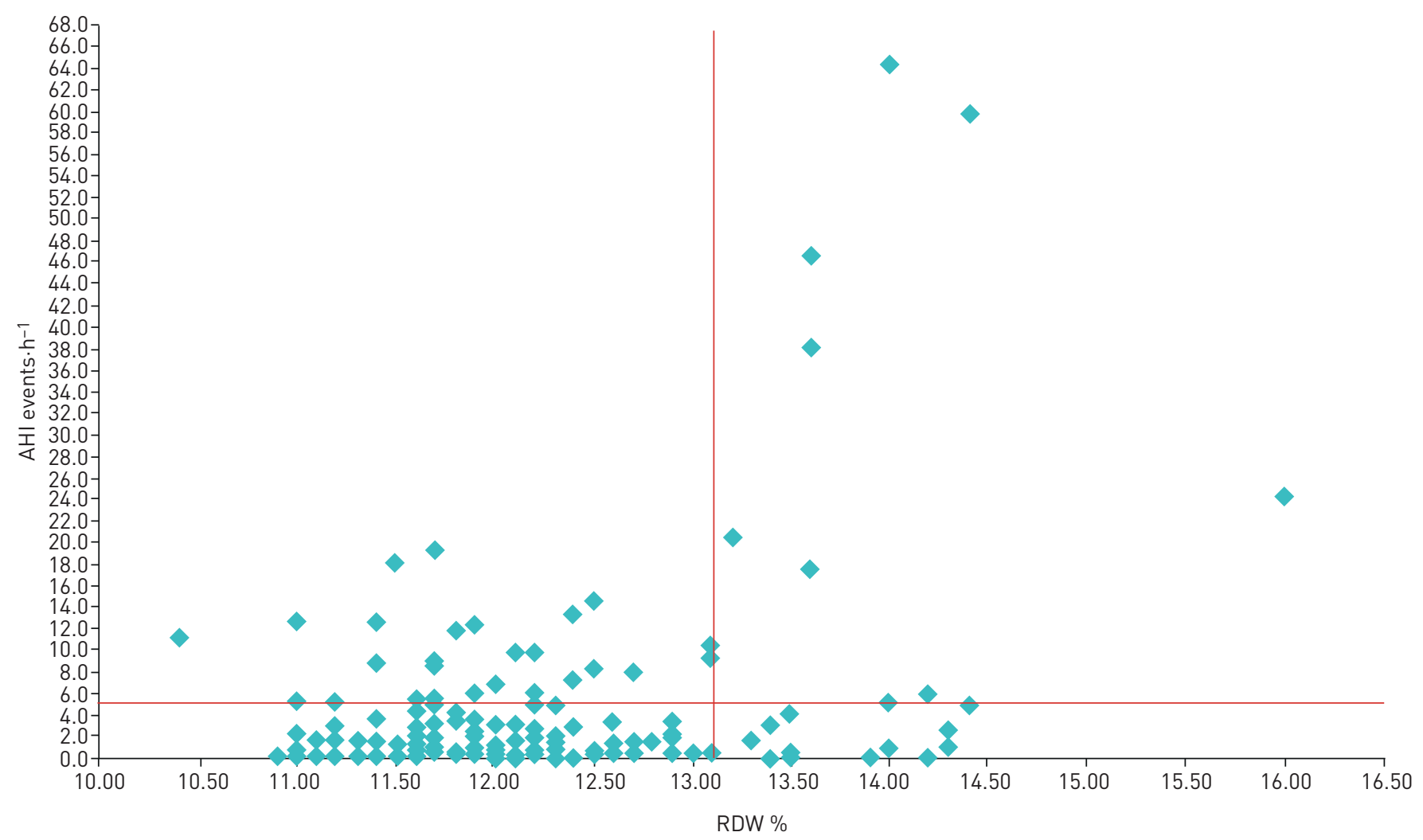

FIGURE 2 Relationship between red cell distribution width (RDW) and apnoea-hypopnoea index (AHI).

shown to correct the increase of urine erythropoietin excretion in individuals with severe OSA [26]. In turn, there is evidence that adenotonsillectomy, a curative treatment in the paediatric population, induces a marked reduction of CRP levels in children independently of obesity, hence evidencing the usefulness of CRP as biomarker for therapeutic monitoring [27].

In our study, the sampled population represents all patients with a suspicion of sleep-breathing disorders and thus includes both phenotypes described in paediatric OSA [28]. The fact that the correlation between RDW and AHI remains significant even after adjusting by age and BMI z-score makes it possible to assign part of those changes to the grade of OSA severity. Based on these results, it seems possible to conclude that OSA induces an alteration in red blood cell production in all paediatric patients, although its role in the pathophysiology and the development of a chronic illness such as cardiovascular disease is yet to be unravelled.

The positive correlation between RDW levels and AHI might enable the use of this biomarker in the severity ranking of OSA. RDW $>14.7 \%$ has been related to a seven-fold increased probability of adverse effects after adenotonsillectomy in paediatric patients with OSA [29]. Relatedly, our results suggest that RDW results above the cut-off of $13.1 \%$, together with $\mathrm{MCHC}$ values, could represent a convenient screening clinical tool for the diagnosis prioritisation, given the correlation to severity of OSA in the paediatric snoring patients. Other studies in adult populations have already pointed out the relationship between RDW and MCHC in the same line as that presented in our study. Furthermore, RDW has been highlighted as a predictor of mortality in different situations such as acute heart failure, and independently related with systemic inflammation [30]. Moreover, in critical paediatric patients, RDW values $>18 \%$ have been suggested as predictors of mortality [31].

Several studies in adult populations have related parameters included in the CBC with OSA severity, and eosinophil count was found to be increased in those groups with more severe OSA.

The concomitance of obesity, OSA and asthma was evaluated in order to better understand the observed increase eosinophil count [32]. In a nonobese paediatric population, there was no association between OSA and asthma control [33]. Our results show a significant association, although negative and extremely weak, between eosinophils and OSA severity. Eosinophil count loses power of prediction in our model after adjusting for age and BMI z-score, which emphasises the importance of obesity as a bidirectional 
factor in OSA studies, as no significant differences between groups were found in the number of asthmatic or allergic sensitisation individuals.

The results of this study reveal that, in the paediatric population, RDW is a blood marker associated with OSA severity and this association is age- and obesity-independent. More biochemical and haematological parameters reflecting secondary alterations are needed, towards an adequate therapeutic approach. In this sense, MCHC as a blood biomarker could offer additional information and could help in clinical diagnosis decision-making.

The diagnosis of OSA is still based on an index derived from a one-night study. For instance, many children aged $<5$ years, in whom the leading problem is adenotonsillar hypertrophy, often show a spontaneous improvement without treatment [34], which may hamper clinical decision-making, especially when surgery is being considered.

It would also be of considerable interest to assess whether RDW levels in OSA patients decrease after establishing the appropriate treatment, towards the levels of non-OSA subjects. It is probable that these alterations are early manifestations in paediatric OSA. Therefore, the reversibility of these alterations after treating OSA would add greater depth to these demonstrated associations.

Other studies in children and teenagers have related increased RDW values to sedentary habits and a lack of moderate physical activity [35]. Accordingly, studies assessing the daily habits of the paediatric population and their relationship with OSA should be planned, as well as the therapeutic capacity of physical activity. In this line, RDW has been associated with OSA severity in adult population [36], and has been suggested to be the only parameter related to comorbidities and their reversibility, due to its close relationship with the systemic inflammatory damage and with the vascular system [37].

In this study, no treatment benefit was demonstrated. This would probably add clarity to the relationships and, perhaps, attribute a greater direct causality to OSA.

\section{Limitations}

The main limitation of our study is the small subgroup size. A population $>38$ patients in severe OSA group may enable a better predictive model to be performed. Since most patients had no OSA or mild OSA in the PSG study, more robust associations are unlikely to be present. Nevertheless, in spite of using a small subgroup, it allows us to point out significant results. Moreover, the individuals included in our study are only snoring children referred to the paediatric pulmonology unit. This might pose a selection bias, and the addition of a nonsnoring control group could strengthen the observed differences.

The lack of quantification of urine or blood erythropoietin levels and no data on the evolution time of the symptoms in the patients in severe OSA group in our study could hamper our conclusions regarding the association between intermittent hypoxia and RDW. However, the wider accessibility of CBC-related data in almost any clinical laboratory makes it of a greater interest and usefulness for the everyday clinical practice compared to erythropoietin, in terms of availability and cost-effectiveness.

\section{Conclusions}

RDW and MCHC were highlighted as a blood markers associated with the severity of paediatric OSA, independently of age and BMI. The fact that this association was observed in snoring patients could help physicians in the distinction between those patients affected or not by moderate-severe OSA. Therefore, the cut-offs of RDW of $13.1 \%$ and $\mathrm{MCHC}$ of $34.9 \mathrm{~g} \cdot \mathrm{dL}^{-1}$ could represent risk factors in the prediction model of moderate-severe paediatric OSA.

Author contributions: N. Toledo-Pons, J.M. Sánchez, J. Peña-Zarza, A. Barceló, J.M. Bauça, D. Morell-Garcia and M. de la Peña-Bravo conceived and designed the study. N. Toledo-Pons, A. Barceló, D. Morell-Garcia, J. Peña-Zarza and P. Giménez supervised the data collection and managed the data, including quality control. N. Toledo-Pons, A. Barceló, D. Morell-Garcia and P. Sanchis provided statistical advice on study design and analysed the data, A. Barceló and M. de la Peña-Bravo chaired the data oversight committee. N. Toledo-Pons, A. Barceló, D. Morell-Garcia and J.M. Bauça drafted the manuscript, and all authors contributed substantially to its revision. D. Morell-Garcia, A. Barceló, N. Toledo-Pons and A. Alonso-Fernández take responsibility for the paper as a whole.

Conflict of interest: D. Morell-Garcia received a grant from Fondo de Investigación Sanitaria during the conduct of the study. N. Toledo-Pons received a grant from Fondo de Investigación Sanitaria during the conduct of the study. P. Sanchis received a grant from Fondo de Investigación Sanitaria during the conduct of the study. J.M. Bauça received a grant from Fondo de Investigación Sanitaria during the conduct of the study. J.M. Sánchez received a grant from Fondo de Investigación Sanitaria during the conduct of the study. J. Peña-Zarza received a grant from Fondo de Investigación Sanitaria during the conduct of the study. P. Giménez received a grant from Fondo de Investigación Sanitaria during the conduct of the study. J. Pierola received a grant from Fondo de Investigación Sanitaria during the conduct of the study. M. de la Peña-Bravo received a grant from Fondo de Investigación Sanitaria during the conduct of the study. 
A. Alonso-Fernández received a grant from Fondo de Investigación Sanitaria during the conduct of the study. A. Barceló received a grant from Fondo de Investigación Sanitaria during the conduct of the study.

Support statement: This work was supported by Fondo de Investigación Sanitaria, Instituto de Salud Carlos III, Spain (grant FIS PI1302120). Funding information for this article has been deposited with the Crossref Funder Registry.

\section{References}

1 American Academy of Sleep Medicine (AASM). International Classification of Sleep Disorders, 3rd edn. Darien, IL, AASM, 2014.

2 Marcus CL, Brooks LJ, Draper KA, et al. Diagnosis and management of childhood obstructive sleep apnea syndrome. Pediatrics 2012; 130: e714-e755.

3 Kaditis AG, Alonso Alvarez ML, Boudewyns A, et al. Obstructive sleep disordered breathing in 2- to 18-year-old children: diagnosis and management. Eur Respir J 2016; 47: 69-94.

4 Saygin M, Ozturk O, Ozguner MF, et al. Hematological parameters as predictors of cardiovascular disease in obstructive sleep apnea syndrome patients. Angiology 2016; 67: 461-470.

5 Salvagno GL, Sanchis-Gomar F, Picanza A, et al. Red blood cell distribution width: a simple parameter with multiple clinical applications. Crit Rev Clin Lab Sci 2015; 52: 86-105.

6 Kurt OK, Yildiz N. The importance of laboratory parameters in patients with obstructive sleep apnea syndrome. Blood Coagul Fibrinolysis 2013; 24: 371-374.

$7 \mathrm{Li} \mathrm{Y,} \mathrm{Li} \mathrm{M,} \mathrm{Teng} \mathrm{Y,} \mathrm{et} \mathrm{al.} \mathrm{The} \mathrm{association} \mathrm{between} \mathrm{red} \mathrm{cell} \mathrm{distribution} \mathrm{width,} \mathrm{erythropoietin} \mathrm{levels,} \mathrm{and} \mathrm{coronary}$ artery disease. Coron Artery Dis 2018; 29: 74-80.

8 Patel KV, Mohanty JG, Kanapuru B, et al. Association of the red cell distribution width with red blood cell deformability. Adv Exp Med Biol 2013; 765: 211-216.

9 Yčas JW, Horrow JC, Horne BD. Persistent increase in red cell size distribution width after acute diseases: a biomarker of hypoxemia? Clin Chim Acta 2015; 448: 107-117.

10 Léon Subías E, Gómara de la Cal S, Marin Trigo JM. Red cell distribution width in obstructive sleep apnea. Arch Bronconeumol 2017; 53: 114-119.

11 Qurtom HA, al-Saleh QA, Lubani MM, et al. The value of red cell distribution width in the diagnosis of anaemia in children. Eur J Pediatr 1989; 148: 745-748.

12 Ferrara M, Capozzi L, Russo R, et al. Reliability of red blood cell indices and formulas to discriminate between beta thalassemia trait and iron deficiency in children. Hematology 2010; 15: 112-115.

13 Chandra H, Shrivastava V, Chandra S, et al. Evaluation of platelet and red blood cell parameters with proposal of modified score as discriminating guide for iron deficiency anemia and $\beta$-thalassemia minor. J Clin Diagn Res 2016; 10: EC31-EC34.

14 Litao MKS, Kamat D. Back to basics: red blood cell distribution width: clinical use beyond hematology. Pediatr Rev 2018; 39: 204-209.

15 López de Lara D, Santiago Paniagua P, Tapia Ruiz M, et al. Valoración del peso, talla e IMC en niños, adolescentes y adultos jóvenes de la Comunidad Autónoma de Madrid. [Evaluation of weight, height and BMI in children, adolescents and young adults from the community of Madrid]. An Pediatr 2010; 73: 305-319.

16 Tomás Vila M, Miralles Torres A, Beseler Soto B. Versión española del Pediatric Sleep Questionnaire. Un instrumento útil en la investigación de los trastornos del sueño en la infancia. Análisis de su fiabilidad. [Spanish version of the Pediatric Sleep Questionnaire (PSQ). A useful instrument in investigation of sleep disturbances in childhood. Reliabilty analysis]. An Pediatr 2007; 66: 121-128.

17 Berry RB, Budhiraja R, Gottlieb DJ, et al. Rules for scoring respiratory events in sleep: update of the 2007 AASM manual for the scoring of sleep and associated events. Deliberations of the sleep apnea definitions task force of the American Academy of Sleep Medicine. J Clin Sleep Med 2012; 8: 597-619.

18 Lumeng JC, Chervin RD. Epidemiology of pediatric obstructive sleep apnea. Proc Am Thorac Soc 2008; 5 $242-252$.

19 Peppard PE, Young T, Barnet JH, et al. Increased prevalence of sleep-disordered breathing in adults. Am J Epidemiol 2013; 177: 1006-1014.

20 Yčas JW. Toward a blood-borne biomarker of chronic hypoxemia: red cell distribution width and respiratory disease. Adv Clin Chem 2017; 82: 105-197.

21 Ryan S, Taylor CT, McNicholas WT. Selective activation of inflammatory pathways by intermittent hypoxia in obstructive sleep apnea syndrome. Circulation 2005; 112: 2660-2667.

22 Ryan S, Taylor CT, McNicholas WT. Predictors of elevated nuclear factor- $\kappa \mathrm{B}$-dependent genes in obstructive sleep apnea syndrome. Am J Respir Crit Care Med 2006; 174: 824-830.

23 Ryan S. Adipose tissue inflammation by intermittent hypoxia: mechanistic link between obstructive sleep apnoea and metabolic dysfunction. J Physiol 2017; 595: 2423-2430.

24 Hall TS, Herrscher TE, Jarolim P, et al. Myeloid-related protein 8/14 and C-reactive protein in individuals evaluated for obstructive sleep apnea. Sleep Med 2014; 15: 762-768.

25 Fleming WE, Holty JEC, Bogan RK, et al. Use of blood biomarkers to screen for obstructive sleep apnea. Nat Sci Sleep 2018; 10: 159-167.

26 Félez M, Grau N, Ruiz A, et al. Increased urinary erythropoietin excretion in severe sleep apnea-hipoapnea syndrome: the effect of CPAP. Arch Bronconeumol 2018; 54: 255-259.

27 Ingram DG, Matthews CK. Effect of adenotonsillectomy on C-reactive protein levels in children with obstructive sleep apnea: a meta-analysis. Sleep Med 2013; 14: 172-176.

28 Dayyat E, Kheirandish-Gozal L, Gozal D. Childhood obstructive sleep apnea: one or two distinct disease entities? Sleep Med Clin 2007; 2: 433-444.

29 Kozanhan B, Iyisoy MS. Red cell distribution width as a novel predictor of postoperative respiratory adverse events after adenotonsillectomy. Paediatr Anaesth 2017; 27: 609-615.

30 Targoński R, Sadowski J, Starek-Stelmaszczyk M, et al. Prognostic significance of red cell distribution width and its relation to increased pulmonary pressure and inflammation in acute heart failure. Cardiol J 2020; 27: 394-403. 
31 Sachdev A, Simalti A, Kumar A, et al. Outcome prediction value of red cell distribution width in critically-ill children. Indian Pediatr 2018; 55: 414-416.

32 Fan Z, Lu X, Long H, et al. The association of hemocyte profile and obstructive sleep apnea. J Clin Lab Anal 2019; 33: e22680.

33 Rogers VE, Bollinger ME, Tulapurkar ME, et al. Inflammation and asthma control in children with comorbid obstructive sleep apnea. Pediatr Pulmonol 2018; 53: 1200-1207.

34 Chervin RD, Ellenberg SS, Hou X, et al. Prognosis for spontaneous resolution of OSA in children. Chest 2015 148: $1204-1213$.

35 Hammam N, Ezeugwu VE, Manns PJ, et al. Relationships between sedentary behaviour, physical activity levels and red blood cell distribution width in children and adolescents. Health Promot Perspect 2018; 8: 147-154.

36 Sunnetcioglu A, Gunbatar H, Ylldız H. Red cell distribution width and uric acid in patients with obstructive sleep apnea. Clin Respir J 2018; 12: 1046-1052.

37 Kivanc T, Kulaksızoglu S, Lakadamyalı $\mathrm{H}$, et al. Importance of laboratory parameters in patients with obstructive sleep apnea and their relationship with cardiovascular diseases. J Clin Lab Anal 2018; 32: e22199. 